\title{
Left ventricular inflow obstruction associated with persistent left superior vena cava and dilated coronary sinus
}

\author{
Daniel J. DiBardino, MD \\ Charles D. Fraser, Jr, MD \\ Heather A. Dickerson, $M D^{b}$ \\ Jeffrey $S$. Heinle, $M D^{a}$ \\ E. Dean McKenzie, $\mathrm{MD}^{\mathrm{a}}$ \\ Grace Kung, $M D^{b}$
}

Background: It has previously been suggested that significant dilatation of the coronary sinus can contribute to left ventricular inflow obstruction and is amenable to surgical correction. The purpose of this study was to review our experience with this rare condition.

Methods: Since 1995, 6 patients have undergone coronary sinus reduction for concerns of obstruction with other concomitant intracardiac repairs. Preoperative echocardiography identified a significantly dilated left superior vena cava to the coronary sinus in 5 patients $(83 \%)$ and an abnormal mitral valve in 4 patients $(67 \%)$; these resulted in abnormal Doppler inflow patterns. Preoperative cardiac catheterization was performed in 5 patients and revealed increased atrial "a" waves, with a gradient to the left ventricular end-diastolic pressure in each case. At the time of surgery, coronary sinus angioplasty was performed in all patients.

Results: There were no deaths, and there was no major morbidity. Follow-up imaging revealed no significant left ventricular inflow obstruction in any patient.

Conclusions: We conclude that dilatation of the coronary sinus can become hemodynamically significant and that coronary sinus angioplasty is a safe and effective technique.

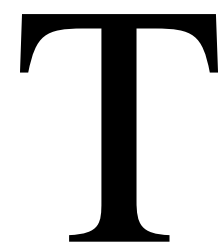

he left-sided superior vena cava (LSVC) is thought to be a remnant of the embryologic left anterior cardinal vein. The prevalence has been reported to be approximately $3 \%$ in isolation and up to $2.8 \%$ to $4.3 \%$ in the presence of congenital heart disease. ${ }^{1}$ The LSVC drains to the coronary sinus (CS), which appears obviously dilated on echocardiography. It has previously been suggested that significant dilatation of the CS can contribute to the obstruction of left ventricular (LV) inflow. ${ }^{2}$ Patients with persistent LSVC and dilated CS (DCS) seem to have a higher incidence of associated left-sided obstructive lesions. ${ }^{3}$ We have observed that although left-sided caval veins are common, DCS potentiating LV inflow obstruction is a rare but real entity that is amenable to surgical correction. The purpose of this study was to review our experience with this unusual problem.

\section{Methods}

A review of our surgical database was performed to include patients with LSVC to DCS who underwent cardiac surgery with reduction angioplasty of the DCS for concerns of left-sided obstruction. As is standard practice at our institution, all patients underwent 2-dimensional transthoracic echocardiography (TTE) with color flow Doppler analysis before surgical referral and a transesophageal echocardiography at the time of operation. Cardiac catheter- 


\section{TABLE 1. Cardiac findings associated with LSVC to DCS}

\begin{tabular}{cl}
\hline $\begin{array}{l}\text { Patient } \\
\text { no. }\end{array}$ & \multicolumn{1}{c}{ Associated cardiac findings } \\
\hline 1 & Perimembranous VSD, supravalvular mitral ring, hypoplastic TV annulus \\
2 & Secundum ASD \\
3 & Secundum ASD, bicuspid AV, MV hypoplasia, LV hypoplasia, ascending \\
& aortic hypoplasia, ${ }^{*}$ coarctation of the aorta* \\
4 & Bicuspid AV, supravalvar mitral ring, abnormal MV leaflets, VSD, ${ }^{*}$ \\
& coarctation of the aorta* \\
5 & Bicuspid AV, supravalvar mitral ring, parachute MV, mild aortic \\
& coarctation \\
6 & TA/VSD, proximal RPA stenosis, distal LPA stenosis
\end{tabular}

$V S D$, Ventricular septal defect; $T V$, tricuspid valve; $A S D$, atrial septal defect; $A V$, aortic valve; $M V$, mitral valve; $L V$, left ventricle; $T A$, tricuspid atresia; $R P A$, right pulmonary artery; $L P A$, left pulmonary artery.

*Previously repaired.

ization was selectively performed for further evaluation of cardiac anatomy and hemodynamic assessment. All preoperative imaging studies were obtained and reviewed with particular attention to left-sided structures. All operative, hospital, and follow-up records were obtained and analyzed. All data are reported as mean values $\pm \mathrm{SD}$.

\section{Results}

\section{Patient Characteristics}

Since 1995, 6 such patients have been identified. The mean age was $6.1 \pm 8.1$ years (range, 0.3-20.2 years), and the mean weight was $24.4 \pm 26.2 \mathrm{~kg}$ (range, $2.2-59.6 \mathrm{~kg}$ ). Three patients had undergone at least 1 previous cardiovascular operation. Associated cardiac findings and previous operations are listed in Table 1. Patients 3, 4, and 5 had Shone syndrome, including various levels of left-sided obstruction from the mitral valve (MV) to the aortic arch.

\section{Preoperative Imaging}

On review of the echocardiograms, LSVC to DCS was found on preoperative TTE in 4 of the 6 patients (Figures 1 and 2). Patient 6 had very poor acoustic windows, and the LSVC to DCS could not be clearly identified on TTE but was obvious on the preoperative transesophageal echocardiogram. In patient 1 , the CS did not appear significantly dilated. Four patients $(67 \%)$ had an abnormal MV; 3 patients $(50 \%)$ had supravalvular mitral rings, and $1(17 \%)$ had a hypoplastic MV annulus (Figure 3). Of the patients with mitral rings, 1 had a parachute MV, and another had abnormal MV leaflets. Patients 1, 4, and 5 had abnormal Doppler inflow patterns. In patient 3, the degree of $\mathrm{LV}$ inflow obstruction was difficult to assess by Doppler echocardiography secondary to the presence of the left-to-right shunt across the atrial septal defect. Five patients $(83 \%)$ underwent preoperative cardiac catheterization, and the LSVC to DCS was identified in each case. The hemodynamic data are summarized in Table 2. Note the presence of an increased left atrial "a" wave with a gradient to the LV end-diastolic pressure, which is indicative of LV inflow obstruction.

\section{Operative Technique}

All 6 patients underwent complete intracardiac repair in addition to CS reduction, as noted in Table 3. Cardiopulmonary bypass was established by either single-stage atrial or separate caval cannulation for venous return. Deep hypothermic circulatory arrest (DHCA) was required in 2 cases. In the first case, right atrial cannulation was used for a 2.2-kg patient, and DHCA allowed intracardiac repair. In the second case, the LSVC could not be cannulated, and DHCA became necessary. In each patient, a severe DCS was noted to straddle the posterior leaflet of the MV and was thought to represent the anatomic substrate for LV inflow obstruction. CS angioplasty was performed by resecting a portion of the anterior wall, and the remaining portion was plicated with running sutures. The mean cardiopulmonary bypass time was $140 \pm 59.7$ minutes (range, 96-253 minutes). The mean aortic crossclamp time was 67 \pm 26.9 minutes (range, 43-101 minutes). DHCA time averaged 33 minutes in 2 patients.

\section{Postoperative Care}

There were no surgical or late deaths. The mean time to extubation was $2.7 \pm 3.8$ days (range, $0-10$ days). The patient who required 10 days of mechanical ventilation had chronic lung disease, and the remainder of her hospital record is unavailable. For the remaining patients, the mean intensive care unit stay was $3.0 \pm 1.4$ days (range, 2-5 days), and the mean hospital stay was $6.4 \pm 2.6$ days (range, 4-10 days). Morbidity included a small pericardial effusion and 1 episode of supraventricular tachycardia. No other major morbidity occurred. 


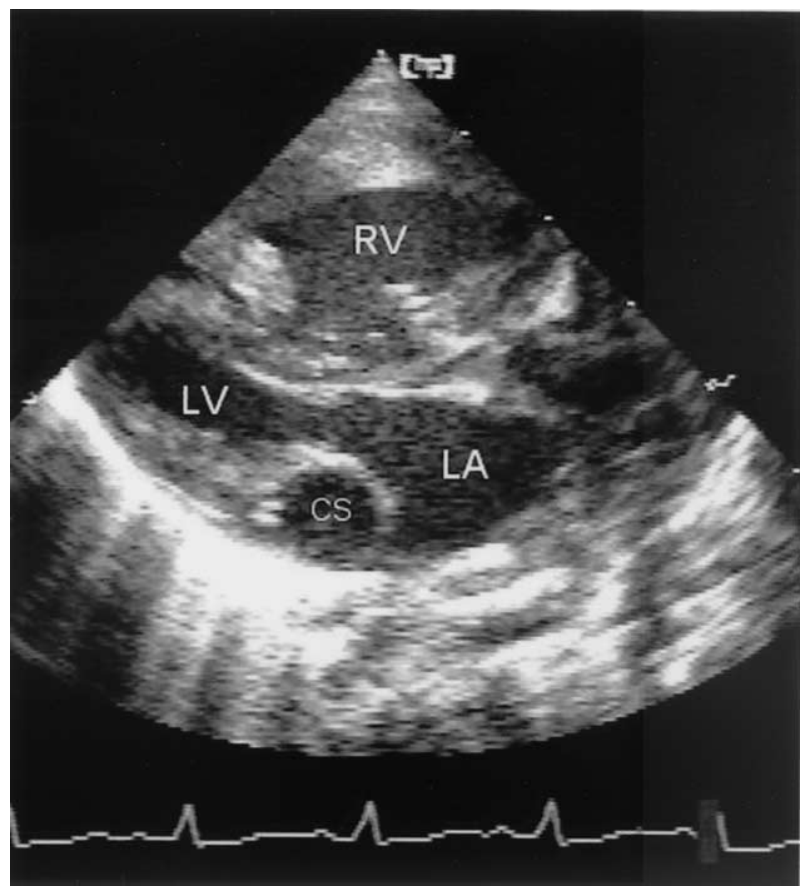

Figure 1. Echocardiographic parasternal long-axis view during diastole, demonstrating the relationship of dilated coronary sinus (CS) to the mitral valve. $L A$, Left atrium; $L V$, left ventricle; $R V$, right ventricle.

TABLE 2. Hemodynamic data at preoperative cardiac catheterization

\begin{tabular}{ccccc}
\hline $\begin{array}{l}\text { Patient } \\
\text { No. }\end{array}$ & $\begin{array}{c}\text { RV pressure } \\
\text { (mm Hg) }\end{array}$ & $\begin{array}{c}\text { LV pressure } \\
\text { (mm Hg) }\end{array}$ & $\begin{array}{c}\text { LA “a" wave } \\
\text { (mm Hg) }\end{array}$ & $\begin{array}{c}\text { LVEDP } \\
\text { (mm Hg) }\end{array}$ \\
\hline 1 & 78 & 110 & 32 & 16 \\
3 & 52 & $92^{*}$ & 15 & $17^{*}$ \\
4 & 100 & 110 & 40 & 15 \\
5 & 45 & $130 \dagger$ & $36 \dagger$ & $12 \dagger$ \\
6 & - & $82^{*}$ & $14 \ddagger$ & $10^{*}$ \\
\hline
\end{tabular}

$R V$, Right ventricle; $L V$, left ventricle; $L A$, left atrium; $L V E D P$, left ventricular end-diastolic pressure.

*After angiography.

†After transseptal procedure.

łLeft pulmonary capillary wedge pressure.

\section{Follow-up and LV Inflow Status}

Follow-up data are available for all patients, with an average follow-up duration of $12.1 \pm 10.9$ months (range, 0.8-26.8 months). There were no late deaths, and all patients are currently asymptomatic from a cardiovascular standpoint. Patients 1, 2, 3, and 6 have no evidence of residual LV inflow obstruction by TTE. Although patient 4 has evidence of mitral stenosis by TTE secondary to the abnormal MV anatomy, a follow-up catheterization revealed no significant gradient across the MV, a right ventricular pressure less than half of the systemic pressure, and a $5 \mathrm{~mm} \mathrm{Hg}$ gradient across the CS. Patient 5 had evidence of mild mitral stenosis

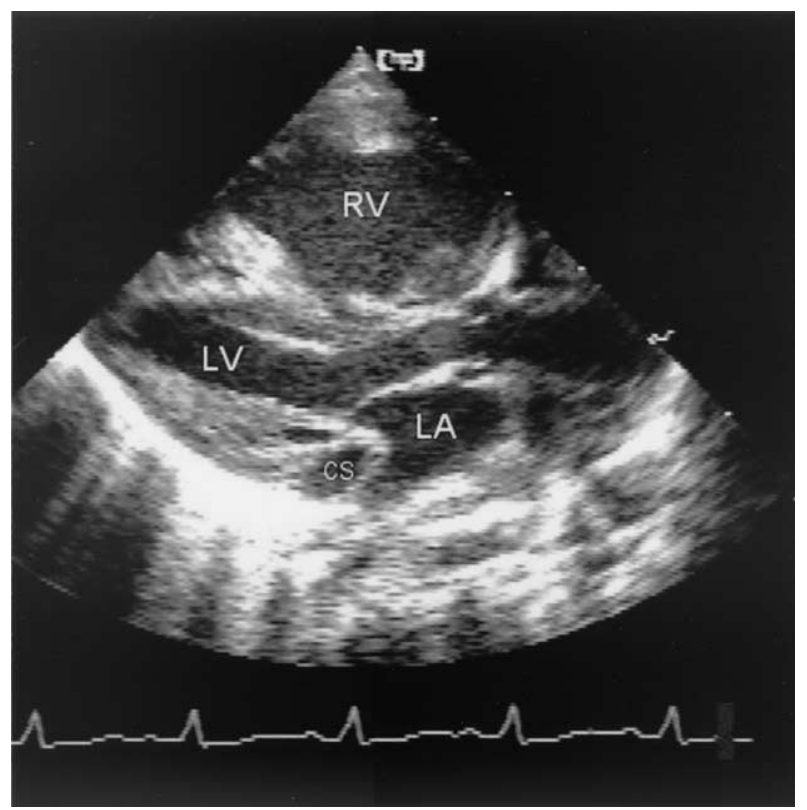

Figure 2. Echocardiographic parasternal long-axis view during systolic contraction, demonstrating the relationship of the dilated coronary sinus (CS) to the mitral valve. $L A$, Left atrium; $L V$, left ventricle; $R V$, right ventricle.

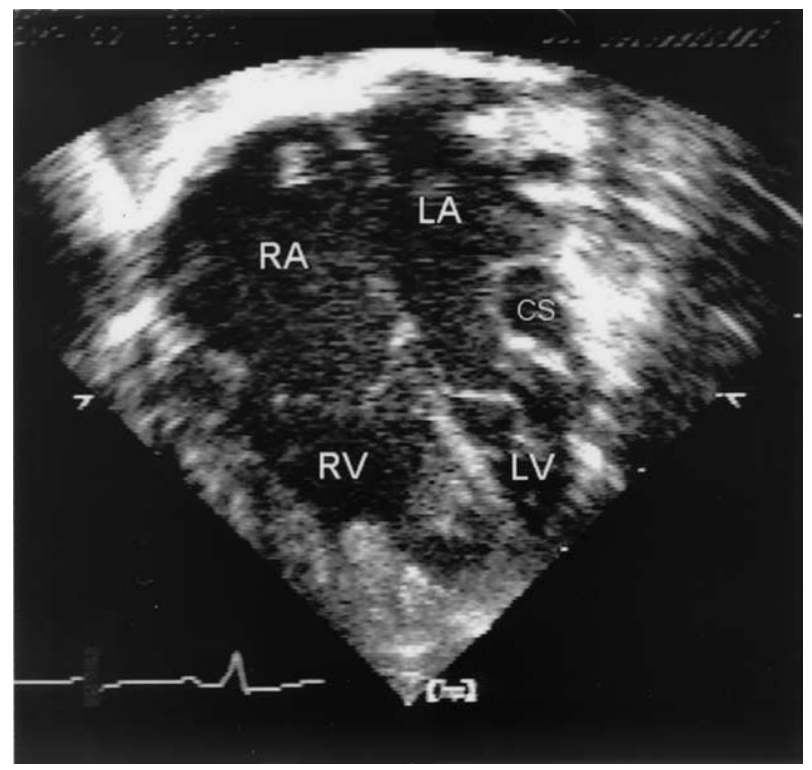

Figure 3. Echocardiographic apical 4-chamber view demonstrating a large coronary sinus (CS) in relation to the hypoplastic mitral valve orifice. $R A$, Right atrium; $R V$, right ventricle; $L A$, left atrium; $L V$, left ventricle.

by TTE with an abnormal parachute MV. Patient 2 had an increase in the pericardial effusion, which eventually necessitated subxiphoid pericardial drainage. 
TABLE 3. Cardiovascular procedures in addition to cutback angioplasty of the DCS

\begin{tabular}{cl}
\hline $\begin{array}{l}\text { Patient } \\
\text { no. }\end{array}$ & \multicolumn{1}{c}{ Additional cardiovascular procedures } \\
\hline 1 & VSD closure, supravalvular mitral ring resection, TV \\
& annuloplasty, PD catheter placement \\
2 & ASD closure \\
3 & ASD closure \\
4 & Supravalvular mitral ring resection \\
5 & PDA ligation, supravalvular ring resection \\
6 & Extracardiac conduit Fontan conversion, modified maze \\
& procedure, atrial septectomy, right atrial debulking, \\
& dual-chamber epicardial pacemaker placement
\end{tabular}

$V S D$, Ventricular septal defect; $T V$, tricuspid valve; $P D$, peritoneal dialysis; $A S D$, atrial septal defect; $P D A$, patent ductus arteriosus.

\section{Discussion}

The presence of an LSVC to a DCS has been proposed to potentiate abnormal hemodynamics. Cochrane and associates $^{2}$ reported on 4 cases of marked DCS overhanging and partially occluding the MV. They postulated that a DCS might potentiate left-to-right shunting at the atrial level in the presence of an atrial septal defect and contribute to LV inflow obstruction, and they proposed correction at the time of cardiac surgery. Although it is difficult to ascribe the precise contribution of the DCS to LV inflow obstruction in the presence of atrial level shunting and associated MV abnormalities, we agree that a severe DCS may worsen LV inflow obstruction and requires reduction. Comas and associates $^{4}$ have commented in a brief letter about 13 such patients at Royal Children's Hospital who have undergone repair with excellent results. There is agreement that reduction and plication is preferred to simple LSVC ligation in this circumstance.

More recent literature suggests that the persistent LSVC may exert a mechanical effect on the developing left side of the heart and lead to a higher incidence of associated left heart obstructive lesions. Autopsy findings have demon- strated a higher prevalence of such lesions in patients with LSVC. ${ }^{5}$ Agnoletti and associates ${ }^{3}$ reviewed catheterization findings and concluded that left-sided obstruction was more prevalent in patients with than without LSVC (39.6\% vs $7.8 \%$, respectively; $P<.001$ ), whereas right-sided obstructive lesions were similar in prevalence. Our experience seems to be consistent with these findings, because 4 patients had an abnormal MV, and 3 had Shone syndrome variants.

On the basis of the available literature and on our experience, there should be a high suspicion for LSVC and DCS in patients with left-sided obstructive lesions and small left-sided heart structures. Persistent LSVC to DCS has been mistaken for both cor triatriatum and posterior LV aneurysm. ${ }^{6,7}$ Careful 2-dimensional echocardiographic analysis can identify the correct anatomy if the suspicion is high. Surgical inspection confirms the anatomic configuration and allows correction with the simple technique of cutback angioplasty. This technique does not seem to add significantly to the operative time and is safe and effective.

\section{References}

1. Lucas RV, Krabill K. Abnormal systemic venous connections. In: Emmanouilides GC, Riemenschneider TA, Allen HD, Gutgesell HP, editors. Moss \& Adams: heart disease in infants, children, and adolescents. Baltimore: Williams \& Wilkins; 1995. p. 875.

2. Cochrane AD, Marath A, Mee RBB. Can a dilated coronary sinus produce left ventricular inflow obstruction? An unrecognized entity. Ann Thorac Surg. 1994;58:1114-6.

3. Agnoletti G, Annecchino F, Preda L, Borghi A. Persistence of the left superior caval vein: can it potentiate obstructive lesions of the left ventricle? Cardiol Young. 1999;9:285-90.

4. Comas JV, Pawade A, Karl TR. Obstruction from persistent superior vena cava. Ann Thorac Surg. 1995;59:793-4.

5. Macedo AJ, Oosthoek PW, Wenink ACG, Bartelings MM. Does persistent left superior vena cava to coronary sinus influence the growth of the left heart in the fetus? Cardiol Young. 1996;6:101.

6. Benatar A, Demanet H, Deuvaert FE. Left-ventricular inflow obstruction due to a dilated coronary sinus mimicking cor triatriatum. Thorac Cardiovasc Surg. 1999;47:127-8.

7. Tirilomis T, Saldana FL, Dalichau H. Dilated coronary sinus mimicking posterior left ventricular aneurysm. Acta Cardiol. 2001;56:199-200. 